\title{
Inhibition of Hydrogen Sulfide Production by Gene Silencing Attenuates Inflammatory Activity by Downregulation of NF- $\kappa$ B and MAP Kinase Activity in LPS-Activated RAW 264.7 Cells
}

\author{
Alireza Badiei, Nethaji Muniraj, Stephen Chambers, and Madhav Bhatia \\ Department of Pathology, University of Otago-Christchurch, P.O. Box 4345, Christchurch 8140, New Zealand \\ Correspondence should be addressed to Madhav Bhatia; madhav.bhatia@otago.ac.nz
}

Received 20 February 2014; Revised 8 July 2014; Accepted 24 July 2014; Published 19 August 2014

Academic Editor: Izumi Takeyoshi

Copyright (c) 2014 Alireza Badiei et al. This is an open access article distributed under the Creative Commons Attribution License, which permits unrestricted use, distribution, and reproduction in any medium, provided the original work is properly cited.

\begin{abstract}
Hydrogen sulfide is an endogenous inflammatory mediator produced by the activity of cystathionine $\gamma$-lyase (CSE) in macrophages. The objective of this study was to explore the mechanism by which hydrogen sulfide acts as an inflammatory mediator in lipopolysaccharide- (LPS-) induced macrophages. In this study, we used small interfering RNA (siRNA) to inhibit CSE expression in macrophages. We found that CSE silencing siRNA could reduce the LPS-induced activation of transcription factor nuclear factor$\kappa \mathrm{B}(\mathrm{NF}-\kappa \mathrm{B})$ significantly. Phosphorylation and activation of extra cellular signal-regulated kinase 1/2 (ERK1/2) increased in LPSinduced macrophages. We showed that phosphorylation of ERK in LPS-induced RAW 264.7 cells reached a peak 30 min after activation. Our findings show that silencing CSE gene by siRNA reduces phosphorylation and activation of ERK1/2 in LPS-induced RAW 264.7 cells. These findings suggest that siRNA reduces the inflammatory effects of hydrogen sulfide through the ERK-NF- $\kappa$ B signalling pathway and hydrogen sulfide plays its inflammatory role through ERK-NF- $\kappa$ B pathway in these cells.
\end{abstract}

\section{Introduction}

Hydrogen sulfide is a toxic gas with a foul odour. It is also now generally accepted that it acts as a gaseous signalling transmitter along with carbon monoxide $(\mathrm{CO})$ and nitric oxide (NO). Hydrogen sulfide is produced in vivo from Lcysteine predominately by cystathionine gamma-lyase (CSE), cystathionine beta synthase (CBS), and 3-mercaptopyruvate sulfurtransferase (3-MST) [1]. Expression of CSE in the periphery [2] and CBS in the central nervous system [3, 4] determines which enzyme is involved in hydrogen sulfide production at these sites. It has been reported that hydrogen sulfide is produced by activity of CSE in macrophages and following this production hydrogen sulfide would induce further activation of macrophages [5-8] suggesting an important role for hydrogen sulfide in the signalling of inflammation.

Inflammation is a defensive mechanism induced by the host in response to injury or infection. Macrophages play a crucial role during inflammation. Activated macrophages have been shown to amplify inflammation via release of proinflammatory mediators such as tumour necrosis factor$\alpha$ (TNF- $\alpha$ ), interleukin-6 (IL-6), and interleukin-1 $\beta$ (IL1$\beta)$. Cytokine secretion induced by hydrogen sulfide has been reported in an in vitro study of human monocytes [9] suggesting an important role for hydrogen sulfide in inflammatory signalling.

Hydrogen sulfide acts as an inflammatory mediator and its levels increase during inflammation. Both exogenously administrated and high level endogenously generated hydrogen sulfides exert proinflammatory activity. It has been reported that hydrogen sulfide may play a proinflammatory role in acute pancreatitis [10, 11], burn injury [12], lipopolysaccharide- (LPS-) induced endotoxemia [13], hemorrhagic shock [14], human monocytes [9], and mouse macrophage [5]. Inhibition of hydrogen sulfide production with a CSE inhibitor, DL-propargylgycine (PAG) [15], and with a CSE gene silencer, small interfering RNA (siRNA) [5], has been shown to ameliorate inflammation suggesting of endogenous hydrogen sulfide has an important role in the pathophysiology of inflammation. 
Macrophages produce and release a wide range of proinflammatory mediators in response to LPS treatment. This depends on inducible gene expression mediated by the activation of mitogen-activated protein kinase (MAPK) and the transcription factor nuclear factor $\kappa \mathrm{B}(\mathrm{NF}-\kappa \mathrm{B})$ [16-18].

$\mathrm{NF}-\kappa \mathrm{B}$ and MAPK cascades play key roles in intracellular signalling pathways involved in cytokines production. Three families of MAPK including c-Jun N-terminal kinase (JNK), extracellular-signal-regulated kinase (ERK), and p38 regulate many genes particularly those of the inflammatory and immune response [19].

Inducible $\mathrm{NF}-\kappa \mathrm{B}$ regulates transcription of immune and inflammatory response genes [20]. NF- $\kappa \mathrm{B}$ is implicated in activation of gene expression for various proinflammatory mediators including TNF- $\alpha$, IL-6, IL- $1 \beta$, and monocyte chemoattractant protein-1 (MCP-1) [21-24].

ERK plays an important role in the temporal control of NF- $\kappa \mathrm{B}$ transcriptional activity and expression of $\mathrm{NF}-\kappa \mathrm{B}$-regulated genes, as well as an upstream activator of $N F-\kappa B[25,26]$. Inhibition of ERK reduced NF- $\kappa B$ transcription activity, suppressed the transcription of NF$\kappa \mathrm{B}$-dependent genes, and protected against LPS-induced endotoxemia $[25,27,28]$. Hydrogen sulfide was shown to activate macrophages with expression and production of proinflammatory cytokines. Strong activation of ERK but not p38 MAPK and JNK was reported in macrophages treated with hydrogen sulfide [29]. Inhibition of ERK resulted in hydrogen sulfide-dependent increase in NF- $\kappa \mathrm{B}$ activity. Therefore, ERK plays an important role in signal transduction of macrophages treated with hydrogen sulfide [29]. Hydrogen sulfide was also shown to regulate the inflammatory response in a mice model of sepsis via activation of the ERK [30]. An in vitro study showed that overexpression of CSE sustainably activates ERK1/2 and p38 MAPK phosphorylation [31]. Zhang and coworkers showed that hydrogen sulfide regulates inflammatory response in a cecal ligation puncture (CLP) model of sepsis through activation of the ERK pathway [30].

In this study, we assess the mechanism by which CSE targeting siRNA downregulates the inflammatory status of monocytes and examine the role of NF- $\kappa \mathrm{B}$ and MAPKs in this process.

\section{Materials and Methods}

2.1. Cell Line and Treatments. The murine macrophage cell line, RAW 264.7 cells, was maintained at $37^{\circ} \mathrm{C}$ in Dullbecco's modified Eagle's medium (DMEM; Gibco BRL, USA) containing 10\% heat inactivated fetal bovine serum (FBS; Gibco BRL, USA) supplemented with penicillin (100 U/mL; Gibco BRL, USA) and streptomycin (100 $\mu \mathrm{g} / \mathrm{mL}$; Gibco BRL, USA). Preliminary experiments demonstrated (data not shown) that the levels of cytokine production were at their optimum $24 \mathrm{~h}$ after administration of LPS (Sigma, Cat. number L-2630) at a concentration of $100 \mathrm{ng} / \mathrm{mL}$. This treatment strategy was therefore used for subsequent experiments in this study.

2.2. siRNA Transfection. Reverse transfection was performed with Lipofectamine RNAiMAX (Invitrogen) as described previously [5]. Briefly, cells $\left(7 \times 10^{5} /\right.$ well $)$ were seeded into a 6 -well plate. At $24 \mathrm{~h}$ after transfection media were replaced with standard media containing serum and antibiotic, and wells designated to the activated group were treated with LPS. Transfection efficiency was confirmed using Block-iT Alexa Fluor Red Fluorescent Oligo (Invitrogen) as per the manufacturer's instructions. We used $50 \mathrm{nM}$ siRNA in our experiments to silence CSE gene expression.

2.3. Nuclear Protein Extraction from Cells. Nuclear protein was extracted according to the protocol from Sigma for nuclear protein extraction without the use of detergent, with minor modifications. The following buffers were prepared to extract the nuclear protein: hypotonic lysis buffer: $10 \mathrm{mM}$ HEPES (pH 7.9), $1.5 \mathrm{mM} \mathrm{MgCl}_{2}, 10 \mathrm{mM} \mathrm{KCl}, 0.1 \mathrm{DTT}$, and protease inhibitor cocktail; extraction buffer: $20 \mathrm{mM}$ HEPES (pH 7.9), $1.5 \mathrm{mM} \mathrm{MgCl}_{2}, 0.42 \mathrm{mM} \mathrm{NaCl}, 0.2 \mathrm{mM}$ EDTA, 25\% glycerol, 0.1 DTT, and protease inhibitor cocktail. Briefly, cells were washed twice with PBS, scraped using fresh PBS, and then centrifuged for $5 \mathrm{~min}$ at $450 \mathrm{~g}$. Pellets were resuspended using $400 \mu \mathrm{L}$ of lysis buffer, incubated for $15 \mathrm{~min}$ at $4^{\circ} \mathrm{C}$, and centrifuged for $5 \mathrm{~min}$ at $420 \mathrm{~g}$. The pellets were resuspended in $250 \mu \mathrm{L}$ lysis buffer and passed through a number-20 gauge needle using a single rapid stroke. Cells were then centrifuged for $20 \mathrm{~min}$ at $5000 \mathrm{~g}$. The pellets were resuspended with $60 \mu \mathrm{L}$ of extraction buffer, shaken for $30 \mathrm{~min}$ at $600 \mathrm{~g}$ at RT, and centrifuged for $5 \mathrm{~min}$ at $11000 \mathrm{~g}$. The supernatants were transferred into fresh tubes and stored at $-70^{\circ} \mathrm{C}$. A DC protein assay (Bio-Rad) was used to determine the protein concentration.

2.4. NF- $\kappa B$ Activity Assay. The binding of NF- $\kappa \mathrm{B}$ to DNA was measured in nuclear extract using an ELISA based TransAmTM NF- $\kappa$ B p 65 transcription factor assay kit (Active Motif) as per the manufacturer's instructions. Briefly, nuclear extracts $(20 \mu \mathrm{g})$ were incubated in a 96-well plate with complete lysis buffer for $1 \mathrm{~h}$ followed by incubation with a specific primary antibody against NF- $\kappa$ B p65 for $1 \mathrm{~h}$. Subsequently, a horse radish peroxidase- (HRP-) conjugated secondary antibody was used for detection. The enzymatic product was measured at $450 \mathrm{~nm}$ using a microplate reader. The specificity of the assay was determined by wild-type or mutated comparative control wells. Results were expressed as fold increase over control groups.

2.5. Western Blot. Nuclear extract proteins were separated on $10 \%$ SDS-polyacrylamide gels and subsequently transferred to PVF membranes. The membranes were blocked for $1 \mathrm{~h}$ in $5 \%$ BSA in Tris-buffered saline containing $0.01 \%$ Tween 20 (TBST). Immunoblotting was performed overnight at $4^{\circ} \mathrm{C}$ with primary antibodies, anti-ERK1/2, and antiphospho-ERK1/2 (Cell Signalling) at a dilution of 1:2000 and $1: 1000$, respectively. Membranes were incubated with a secondary horseradish peroxidase-conjugated antibody at $1: 10000$ dilutions for $1 \mathrm{~h}$ at room temperature. To visualize immunoreactive proteins, the enhanced chemiluminescence 


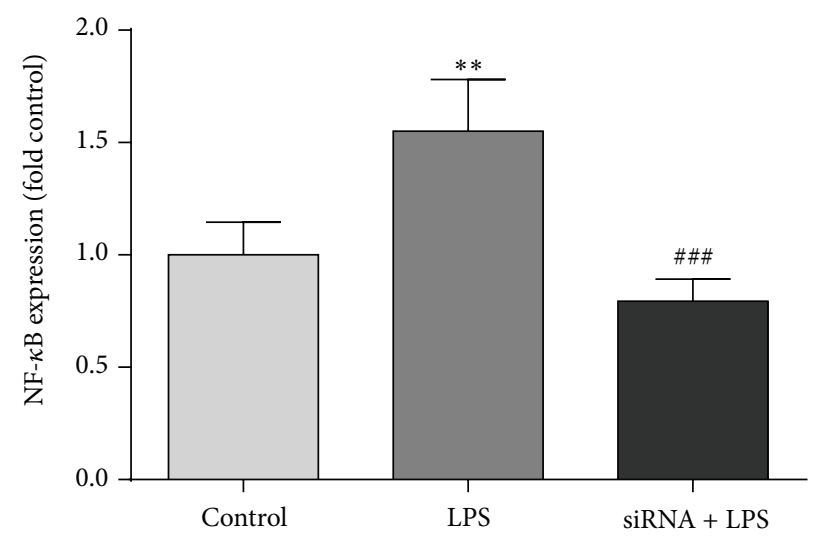

FIGURE 1: The effect of LPS and siRNA on NF- $\kappa$ B activity. NF- $\kappa$ B activity is expressed as a fold control. The control group is untreated, the LPS group has received $100 \mathrm{ng} / \mathrm{mL}$ LPS $24 \mathrm{~h}$ prior to assay, and the LPS + siRNA group has received $50 \mu \mathrm{M}$ siRNA $24 \mathrm{~h}$ prior to LPS treatment which was administrated $24 \mathrm{~h}$ prior to assay. For all groups $N=3$. Error is SD. ${ }^{* *} P<0.01$ compared to control and ${ }^{\# \#} P<0.001$ compared to LPS using planned comparisons.

detection kit (PerkinElmer, USA) was used. Hypoxanthineguanine phosphoribosyl transferase (HPRT) (Santa Cruz Biotechnology) was used as the housekeeping protein.

2.6. Statistics. To analyse the data one way ANOVA and Tukey's multiple comparison tests were used. The experiments were performed in triplicate and the results are expressed as mean \pm SD. $P$ values $<0.05$ were regarded as statistically significant.

\section{Results}

3.1. Inhibition of NF- $\kappa B$ Activity by siRNA in RAW 264.7 Cells. The NF- $\kappa \mathrm{B}$ pathway is essential for the activation of most inflammatory genes. To examine whether the NF$\kappa \mathrm{B}$ signal transduction pathway is involved in LPS-induced CSE expressions, RAW 264.7 cells were stimulated with LPS following treatment with siRNA. Analysis of the NF$\kappa \mathrm{B}$ DNA binding assay revealed that the levels of the NF$\kappa \mathrm{B}$ activity in the LPS-induced (100 ng/mL) RAW 264.7 cells were significantly higher than untreated cells. NF- $\kappa$ B DNA binding assay analysis demonstrated that the levels of NF$\kappa \mathrm{B}$ activity in the LPS-induced $(100 \mathrm{ng} / \mathrm{mL})$ RAW 264.7 cells pretreated with siRNA reduced significantly compared to untreated cells. There was a significant effect of LPS and siRNA treatment on NF- $\kappa$ B expression in RAW 264.7 macrophages $(F(2,9)=21.85 ; P<0.001)$ (Figure 1). LPS treatment $24 \mathrm{~h}$ prior to NF- $\kappa \mathrm{B}$ DNA binding assay resulted in a significantly higher level of NF- $\kappa$ B expression with levels 1.5 -fold $(0.23 \mathrm{SD})$ higher than control $(P<0.01)$ (Figure 1$)$. siRNA administration reduced the effect of LPS on NF- $\kappa \mathrm{B}$ expression to 0.8 -fold $(0.9 \mathrm{SD})$ lower than $\operatorname{control}(P<0.001)$ (Figure 1).

3.2. Effect of CSE Targeting siRNA on the Phosphorylation of MAP Kinase. Activated macrophages are induced by three families of MAP kinase. These kinase families play an important role in cell growth, stress induced gene expression, and differentiation $[32,33]$.

Before the siRNA experiments could be performed in the time course of phosphorylation following LPS activation, the phosphorylation needed to be established. To elucidate this, an experiment was performed where LPS was administered at various time periods and cell lysates were analysed for phosphorylation of ERK1/2. Our results showed that the enhanced phosphorylation of ERK1/2 was found as early as $15 \mathrm{~min}$ after treating cells with LPS and persisted for $15 \mathrm{~min}$ (Figure 2).

Using this time point (30 min), we examined the effect of CSE targeting siRNA on the phosphorylation of ERK MAP kinase. Our results showed that siRNA targeting CSE inhibited LPS-induced phosphorylation of ERK1/2 (Figure 3). These results revealed that siRNA has inhibitory effects on the production of the inflammatory mediators through inhibition of MAP kinase ERK1/2 phosphorylation.

\section{Discussion}

Hydrogen sulfide is an inflammatory mediator with an important role in normal physiology and disease. Elevated levels of hydrogen sulfide [34] and increased CSE mRNA expression $[5,8]$ following LPS administration have been shown. In a previous study [5] we demonstrated that transfection of siRNA in RAW 264.7 cells resulted in lower levels of CSE mRNA and protein expression as well as reduced levels of proinflammatory mediators. In this study, the mechanism by which hydrogen sulfide acts as a proinflammatory mediator was examined using LPS-activated RAW 264.7 cells pretreated with siRNA. In this experiment, we used $50 \mathrm{nM}$ siRNA to silence CSE gene expression. Cell viability assay showed that this dose of siRNA had no cytotoxic effects on RAW 264.7 cells [5]. 


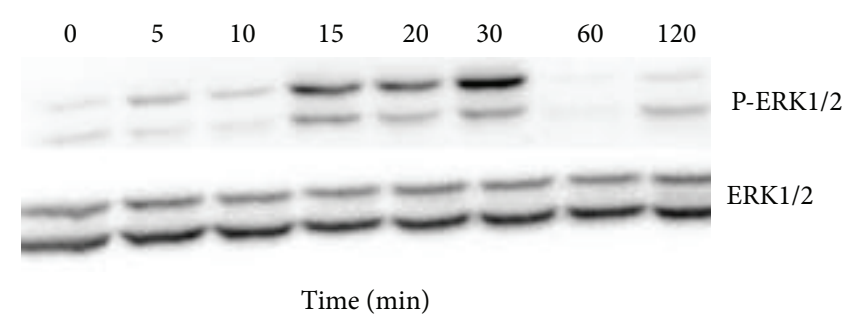

(a)

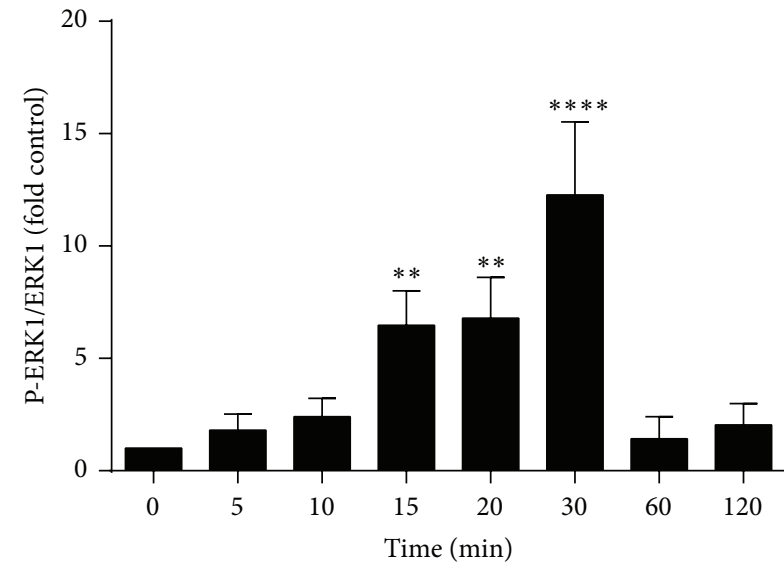

(b)

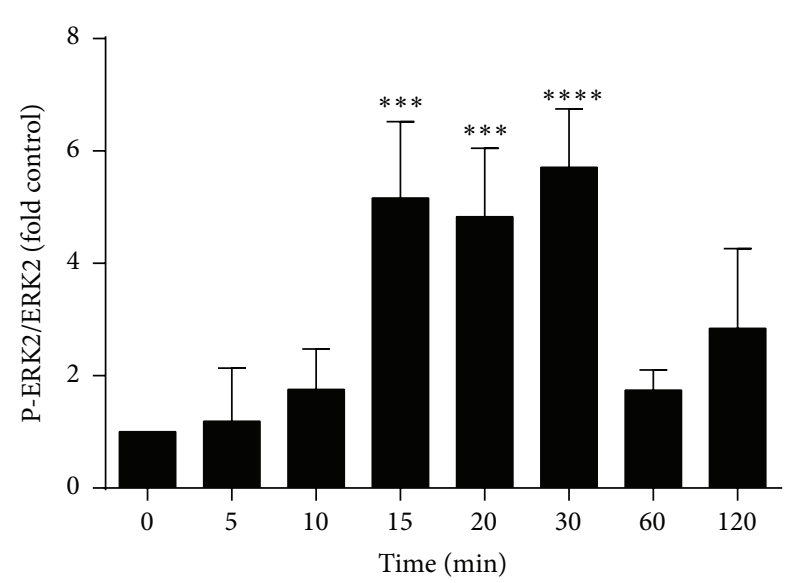

(c)

FIGURE 2: LPS induces phosphorylation of ERK1/2 in a time-dependent manner. RAW 264.7 cells were incubated with $100 \mathrm{ng} / \mathrm{mL} \mathrm{LPS}$ for 0-24 h. Total cell lysates were examined by western blot with anti-ERK1/2 and phosphor-ERK1/2 (P-ERK) antibodies. (a) Results shown are representative blots from three different experiments. (b and c) The histograms represent the optical density of phosphor-ERK1/2: total ERK1/2 expressed as control fold increase. Results shown are the mean \pm SD of the three experiments. ${ }^{* * *} P<0.0001,{ }^{* * *} P<0.001$, and ${ }^{* *} P<0.01$ compared to control.

Treatment of macrophages with LPS triggers the activation of various signalling pathways among which the MAPKs family play a significant role in inflammation. Phosphorylation of ERK increased as early as $15 \mathrm{~min}$ after LPS treatment and reached a peak at 30 min which was in accordance with previous reports $[35,36]$. However, it is of interest to note that inhibition of hydrogen sulfide production by silencing the CSE gene using siRNA in cells treated with LPS for $30 \mathrm{~min}$ resulted in reduced phosphorylation of ERK.

$\mathrm{NF}-\kappa \mathrm{B}$ plays an important role as a central transcription factor regulating the transcription of many proinflammatory cytokines, chemokines, and adhesion molecules. NF- $\kappa \mathrm{B}$ is present in the cytoplasm where it exists in an inactive state, bound to an inhibitory protein $\kappa \mathrm{B}(\mathrm{I} \kappa \mathrm{B})$. Upon activation, $\mathrm{NF}-\kappa \mathrm{B}$ dissociates from I $\kappa \mathrm{B}$ and translocates into the nucleus where it binds to 10-bp sequences in the regulatory regions of several inflammatory genes, upregulating their transcription $[37,38]$.

Recently, NF- $\kappa \mathrm{B}$ has been shown to be involved in TLR4-mediated upregulation of CSE mRNA expression and generation of hydrogen sulfide in LPS-induced macrophages [36]. In accordance with this report, our findings also suggest that NF- $\kappa$ B plays a key role in the inflammatory response of
LPS-induced macrophages. In this study, we also demonstrated that inhibition of CSE gene expression by siRNA resulted in a decreased NF- $\kappa$ B activation in LPS-induced macrophages. In a previous report, we have demonstrated the downregulation of inflammatory mediators by silencing the CSE gene with siRNA. Our findings show that siRNA targeting CSE reduced inflammation status by reducing the activity of NF- $\kappa \mathrm{B}$. These findings indicate that inhibition of proinflammatory mediator production by LPS-induced RAW 264.7 cells may involve transcriptional regulation through suppression of NF- $\kappa \mathrm{B}-\mathrm{DNA}$ binding potential and interference with nuclear translocation of NF- $\kappa$ B.

Previously it has been shown that hydrogen sulfide could activate NF- $\kappa \mathrm{B}$ in human monocyte cells, U937 cells, via degradation of $\mathrm{I} \kappa \mathrm{B}-\alpha$ [9]. The results of our present study are consistent with this report as we found that hydrogen sulfide and LPS-induced RAW 264.7 cells increase the activity of NF- $\kappa \mathrm{B}$, and this effect was attenuated by siRNA against CSE. Therefore, hydrogen sulfide induces NF- $\kappa \mathrm{B}$ activation and acts as a proinflammatory mediator in macrophages.

In conclusion, this study shows that CSE-targeted siRNA inhibited NF- $\kappa \mathrm{B}$ activation and ERK phosphorylation in LPS-induced macrophages and, consequently, downregulates 


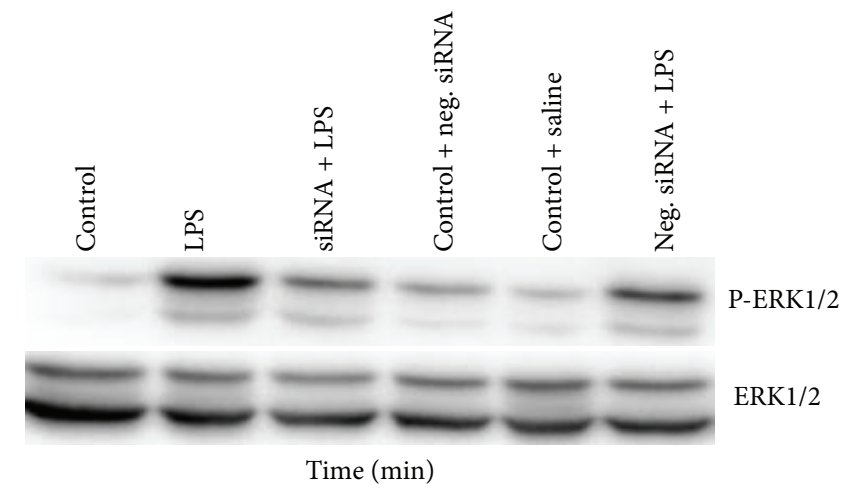

(a)

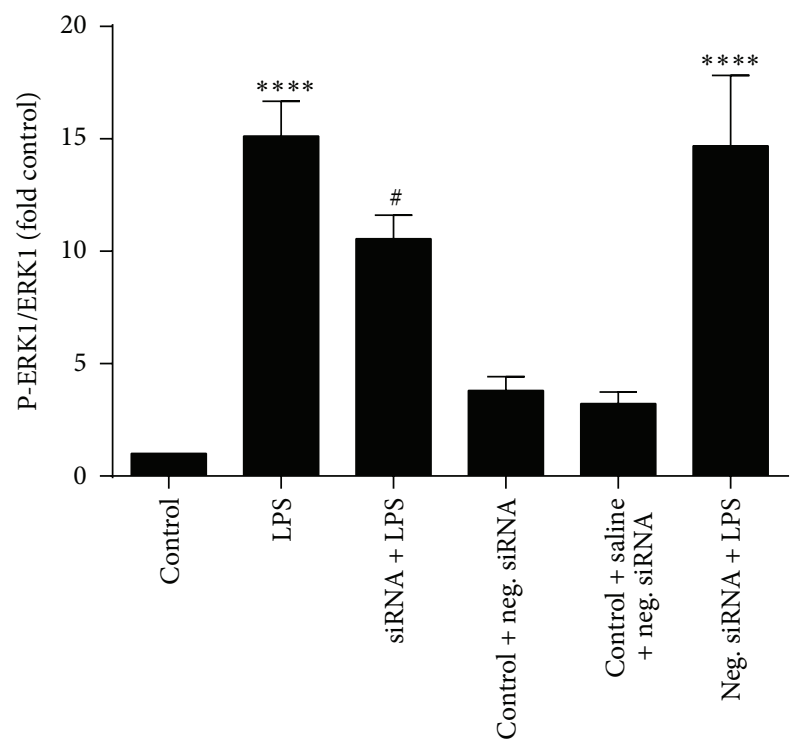

(b)

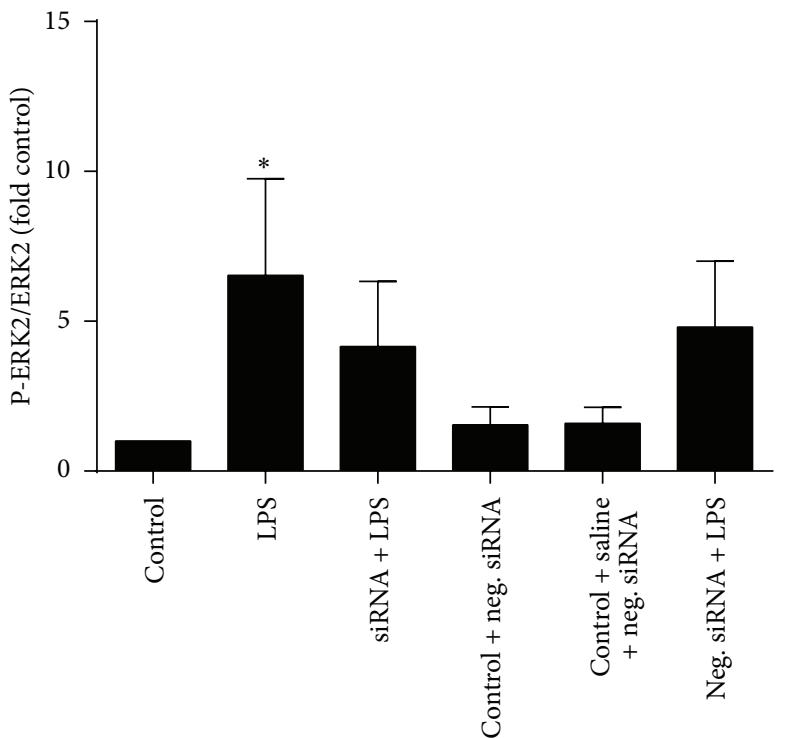

(c)

FIgURE 3: The effect of siRNA on the phosphorylation of ERK1/2 in RAW 264.7 cells macrophages. Cells were incubated with $100 \mathrm{ng} / \mu \mathrm{L}$ LPS for $30 \mathrm{~min}$ and cell lysates were examined by western blot using anti-ERK1/2 and phosphor-ERK1/2 (P-ERK) antibodies. (a) Results shown are representative blots from three independent experiments. (b and c) The histograms represent the ratios of the optical density of phosphor-ERK1/2: total ERK1/2 expressed as fold control. Data shown are the mean \pm SD of the three experiments.

proinflammatory mediator secretion by LPS-induced macrophages. This indicates that hydrogen sulfide acts as an inflammatory mediator through ERK-NF- $\kappa$ B pathway.

\section{Conflict of Interests}

The authors declare that there is no conflict of interests regarding the publication of this paper.

\section{Acknowledgments}

The authors gratefully acknowledge the financial support of the University of Otago, Christchurch. This work was supported by an establishment grant from Professor Madhav Bhatia.

\section{References}

[1] A. F. Perna, M. G. Luciano, D. Ingrosso et al., "Hydrogen sulfide, the third gaseous signaling molecule with cardiovascular properties, is decreased in hemodialysis patients," Journal of Renal Nutrition, vol. 20, supplement, no. 5, pp. S11-S14, 2010.

[2] P. K. Moore, M. Bhatia, and S. Moochhala, "Hydrogen sulfide: from the smell of the past to the mediator of the future?" Trends in Pharmacological Sciences, vol. 24, no. 12, pp. 609-611, 2003.

[3] H. Zhao, J. Q. Wang, T. Shimohata et al., "Conditions of protection by hypothermia and effects on apoptotic pathways in a rat model of permanent middle cerebral artery occlusion," Journal of Neurosurgery, vol. 107, no. 3, pp. 636-641, 2007.

[4] Y. Enokido, E. Suzuki, K. Iwasawa, K. Namekata, H. Okazawa, and H. Kimura, "Cystathionine $\beta$-synthase, a key enzyme for homocysteine metabolism, is preferentially expressed in the 
radial glia/astrocyte lineage of developing mouse CNS," The FASEB Journal, vol. 19, no. 13, pp. 1854-1856, 2005.

[5] A. Badiei, J. Rivers-Auty, A. D. Ang, and M. Bhatia, "Inhibition of hydrogen sulfide production by gene silencing attenuates inflammatory activity of LPS-activated RAW264.7 cells," Applied Microbiology and Biotechnology, vol. 97, no. 17, pp. 78457852, 2013.

[6] T. W. Miller, E. A. Wang, S. Gould et al., "Hydrogen sulfide is an endogenous potentiator of T cell activation," The Journal of Biological Chemistry, vol. 287, no. 6, pp. 4211-4221, 2012.

[7] G. S. Oh, H. Pae, B. Lee et al., "Hydrogen sulfide inhibits nitric oxide production and nuclear factor- $\kappa \mathrm{B}$ via heme oxygenase-1 expression in RAW264.7 macrophages stimulated with lipopolysaccharide," Free Radical Biology and Medicine, vol. 41, no. 1, pp. 106-119, 2006.

[8] X.-Y. Zhu, S.-J. Liu, Y.-J. Liu, S. Wang, and X. Ni, "Glucocorticoids suppress cystathionine gamma-lyase expression and $\mathrm{H}_{2} \mathrm{~S}$ production in lipopolysaccharide-treated macrophages," Cellular and Molecular Life Sciences, vol. 67, no. 7, pp. 1119-1132, 2010.

[9] L. Zhi, A. D. Ang, H. Zhang, P. K. Moore, and M. Bhatia, "Hydrogen sulfide induces the synthesis of proinflammatory cytokines in human monocyte cell line U937 via the ERK-NF$\kappa \mathrm{B}$ pathway," Journal of Leukocyte Biology, vol. 81, no. 5, pp. 1322-1332, 2007.

[10] R. Tamizhselvi, P. Shrivastava, Y. Koh, H. Zhang, and M. Bhatia, "Preprotachykinin-A gene deletion regulates hydrogen sulfideinduced Toll-like receptor 4 signaling pathway in ceruleintreated pancreatic acinar cells," Pancreas, vol. 40, no. 3, pp. 444452, 2011.

[11] M. Bhatia, J. N. Sidhapuriwala, S. Wei Ng, R. Tamizhselvi, and S. M. Moochhala, "Pro-inflammatory effects of hydrogen sulphide on substance P in caerulein-induced acute pancreatitis," Journal of Cellular and Molecular Medicine, vol. 12, no. 2, pp. 580-590, 2008.

[12] J. Zhang, S. W. S. Sio, S. Moochhala, and M. Bhatia, "Role of hydrogen sulfide in severe burn injury-induced inflammation in mice," Molecular Medicine, vol. 16, no. 9-10, pp. 417-424, 2010.

[13] F. Anuar, M. Whiteman, L. S. Jia, E. K. Shing, M. Bhatia, and P. K. Moore, "Nitric oxide-releasing flurbiprofen reduces formation of proinflammatory hydrogen sulfide in lipopolysaccharidetreated rat," British Journal of Pharmacology, vol. 147, no. 8, pp. 966-974, 2006.

[14] Y. P. Mok and P. K. Moore, "Hydrogen sulphide is pro-inflammatory in haemorrhagic shock," Inflammation Research, vol. 57, no. 11, pp. 512-518, 2008.

[15] R. Tamizhselvi, P. K. Moore, and M. Bhatia, "Inhibition of hydrogen sulfide synthesis attenuates chemokine production and protects mice against acute pancreatitis and associated lung injury," Pancreas, vol. 36, no. 4, pp. e24-e31, 2008.

[16] X. Ci, Y. Song, F. Zeng et al., "Ceftiofur impairs pro-inflammatory cytokine secretion through the inhibition of the activation of NF- $\kappa \mathrm{B}$ and MAPK," Biochemical and Biophysical Research Communications, vol. 372, no. 1, pp. 73-77, 2008.

[17] X. Zhang, Y. Song, X. Ci et al., "Effects of florfenicol on early cytokine responses and survival in murine endotoxemia," International Immunopharmacology, vol. 8, no. 7, pp. 982-988, 2008.

[18] X. Zhang, H. Li, H. Feng et al., "Valnemulin downregulates nitric oxide, prostaglandin E2, and cytokine production via inhibition of NF- $\kappa \mathrm{B}$ and MAPK activity," International Immunopharmacology, vol. 9, no. 7-8, pp. 810-816, 2009.
[19] Y. S. Kim, Y. Ahn, M. H. Hong et al., "Curcumin attenuates inflammatory responses of TNF-alpha-stimulated human endothelial cells," Journal of Cardiovascular Pharmacology, vol. 50, no. 1, pp. 41-49, 2007.

[20] Q. Li and I. M. Verma, "NF-kappaB regulation in the immune system," Nature Reviews Immunology, vol. 2, no. 10, pp. 725-734, 2002.

[21] A. N. Shakhov, M. A. Collart, P. Vassalli, S. A. Nedospasov, and $\mathrm{C}$. V. Jongeneel, " $\kappa \mathrm{B}$-type enhancers are involved in lipopolysaccharide-mediated transcriptional activation of the tumor necrosis factor $\alpha$ gene in primary macrophages," Journal of Experimental Medicine, vol. 171, no. 1, pp. 35-47, 1990.

[22] T. Sun, J. Luo, M. Jia, H. Li, K. Li, and Z. Fu, "Small interfering RNA-mediated knockdown of NF- $\kappa$ Bp65 attenuates neuropathic pain following peripheral nerve injury in rats," European Journal of Pharmacology, vol. 682, no. 1-3, pp. 79-85, 2012.

[23] R. Donadelli, M. Abbate, C. Zanchi et al., "Protein traffic activates NF-kB gene signaling and promotes MCP-1-dependent interstitial inflammation," American Journal of Kidney Diseases, vol. 36, no. 6, pp. 1226-1241, 2000.

[24] A. Ueda, K. Okuda, S. Ohno et al., "NF- $\kappa$ B and Sp1 regulate transcription of the human monocyte chemoattractant protein1 gene," The Journal of Immunology, vol. 153, no. 5, pp. 20522063, 1994.

[25] B. Jiang, S. Xu, X. Hou, D. R. Pimentel, P. Brecher, and R. A. Cohen, "Temporal control of NF- $\kappa$ B activation by ERK differentially regulates interleukin- $1 \beta$-induced gene expression," The Journal of Biological Chemistry, vol. 279, no. 2, pp. 1323-1329, 2004.

[26] P. P. Roux and J. Blenis, "ERK and p38 MAPK-activated protein kinases: a family of protein kinases with diverse biological functions," Microbiology and Molecular Biology Reviews, vol. 68, no. 2, pp. 320-344, 2004.

[27] C. D. Dumitru, J. D. Ceci, C. Tsatsanis et al., "TNF- $\alpha$ induction by LPS is regulated posttranscriptionally via a Tpl2/ERKdependent pathway," Cell, vol. 103, no. 7, pp. 1071-1083, 2000.

[28] M. S. Choi, S. H. Lee, H. S. Cho et al., "Inhibitory effect of obovatol on nitric oxide production and activation of NF- $\kappa \mathrm{B} / \mathrm{MAP}$ kinases in lipopolysaccharide-treated RAW 264.7cells," European Journal of Pharmacology, vol. 556, no. 1-3, pp. 181-189, 2007.

[29] L. Zhi, A. D. Ang, H. Zhang, P. K. Moore, and M. Bhatia, "Hydrogen sulfide induces the synthesis of proinflammatory cytokines in human monocyte cell line U937 via the ERK-NF$\kappa \mathrm{B}$ pathway," Journal of Leukocyte Biology, vol. 81, no. 5, pp. 1322-1332, 2007.

[30] H. Zhang, S. M. Moochhala, and M. Bhatia, "Endogenous hydrogen sulfide regulates inflammatory response by activating the ERK pathway in polymicrobial sepsis," Journal of Immunology, vol. 181, no. 6, pp. 4320-4331, 2008.

[31] G. Yang, K. Cao, L. Wu, and R. Wang, "Cystathionine $\gamma$-lyase overexpression inhibits cell proliferation via a H2S-dependent modulation of ERK1/2 phosphorylation and p21 Cip/WAK-1," The Journal of Biological Chemistry, vol. 279, no. 47, pp. 4919949205, 2004.

[32] J. Raingeaud, S. Gupta, J. S. Rogers et al., "Pro-inflammatory cytokines and environmental stress cause p38 mitogen- activated protein kinase activation by dual phosphorylation on tyrosine and threonine," The Journal of Biological Chemistry, vol. 270, no. 13, pp. 7420-7426, 1995.

[33] M. H. Cobb, "MAP kinase pathways," Progress in Biophysics and Molecular Biology, vol. 71, no. 3-4, pp. 479-500, 1999. 
[34] X. Zhu, S. Liu, Y. Liu, S. Wang, and X. Ni, "Glucocorticoids suppress cystathionine gamma-lyase expression and $\mathrm{H}_{2} \mathrm{~S}$ production in lipopolysaccharide-treated macrophages," Cellular and Molecular Life Sciences, vol. 67, no. 7, pp. 1119-1132, 2010.

[35] S. Bhattacharyya, D. E. Brown, J. A. Brewer, S. K. Vogt, and L. J. Muglia, "Macrophage glucocorticoid receptors regulate Tolllike receptor 4-mediated inflammatory responses by selective inhibition of p38 MAP kinase," Blood, vol. 109, no. 10, pp. 43134319, 2007.

[36] Y. Zheng, N. Luo, D. Mu et al., "Lipopolysaccharide regulates biosynthesis of cystathionine $\gamma$-lyase and hydrogen sulfide through toll-like receptor-4/p38 and toll-like receptor-4/NF- $\kappa \mathrm{B}$ pathways in macrophages," In Vitro Cellular \& Developmental Biology: Animal, vol. 49, no. 9, pp. 679-688, 2013.

[37] P. A. Baeuerle and D. Baltimore, "I $\kappa \beta$ : a specific inhibitor of the NF- $\kappa$ B transcription factor," Science, vol. 242 , no. 4878 , pp. $540-$ $546,1988$.

[38] M. Karin and Y. Ben-Neriah, "Phosphorylation meets ubiquitination: the control of NF- $\kappa \mathrm{B}$ activity," Annual Review of Immunology, vol. 18, pp. 621-663, 2000. 


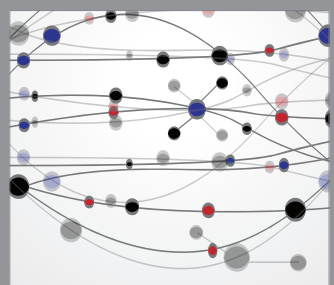

The Scientific World Journal
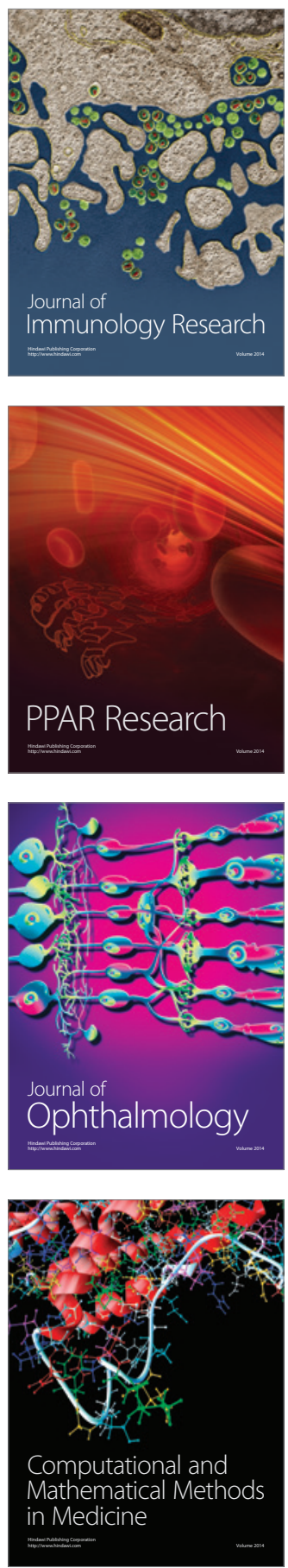

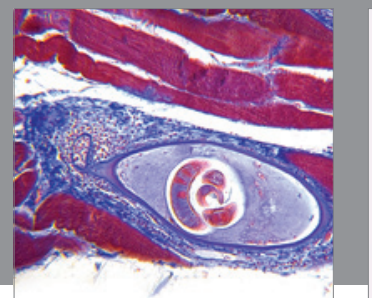

Gastroenterology

Research and Practice
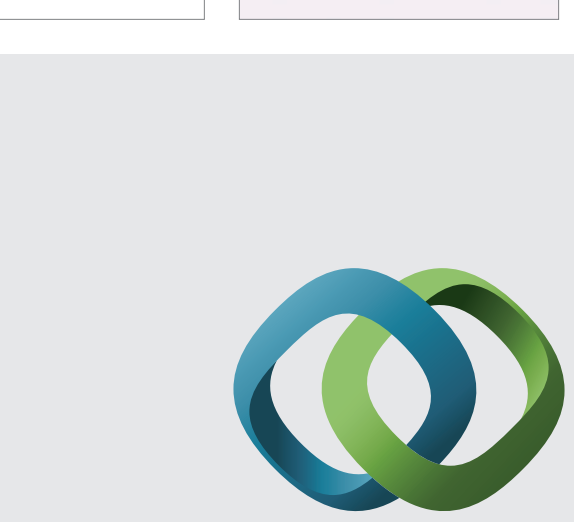

\section{Hindawi}

Submit your manuscripts at

http://www.hindawi.com
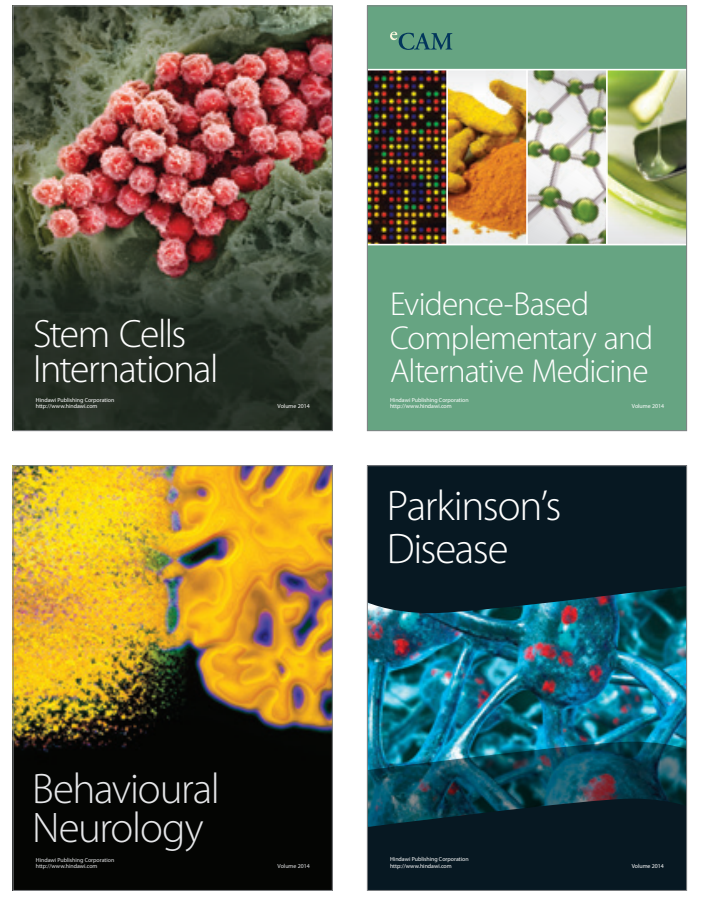
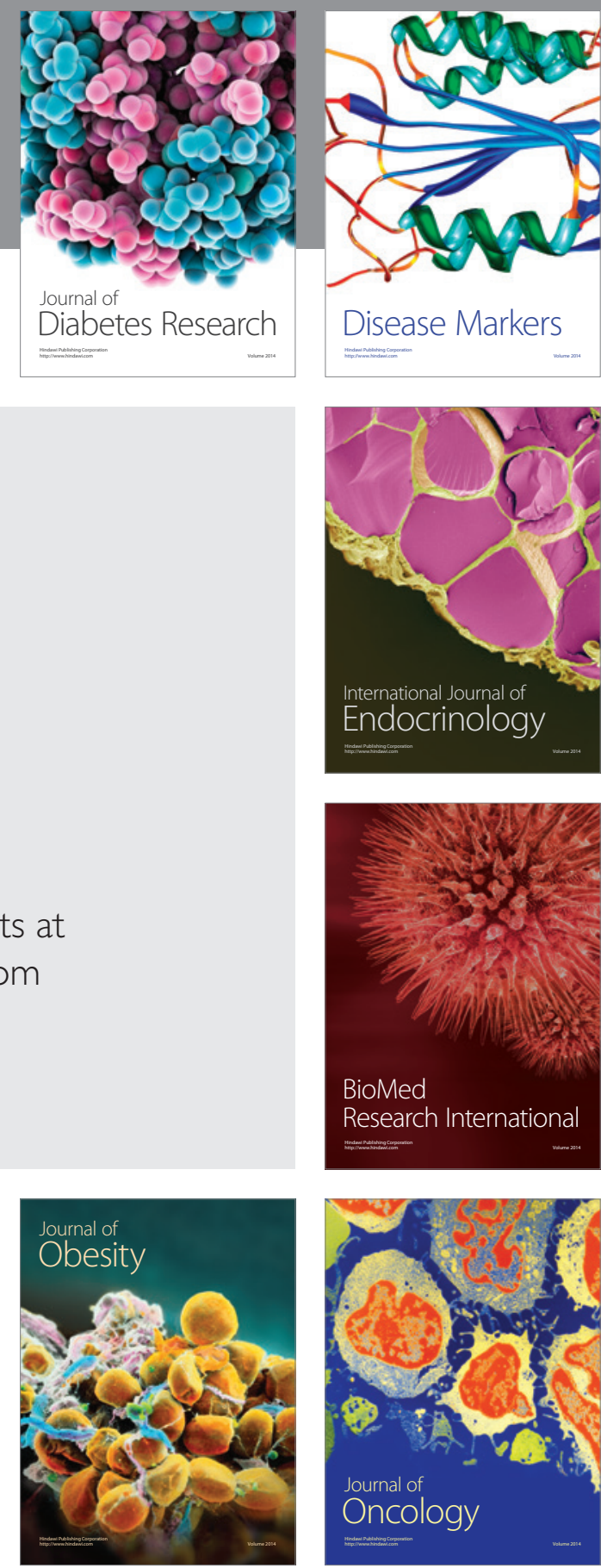

Disease Markers
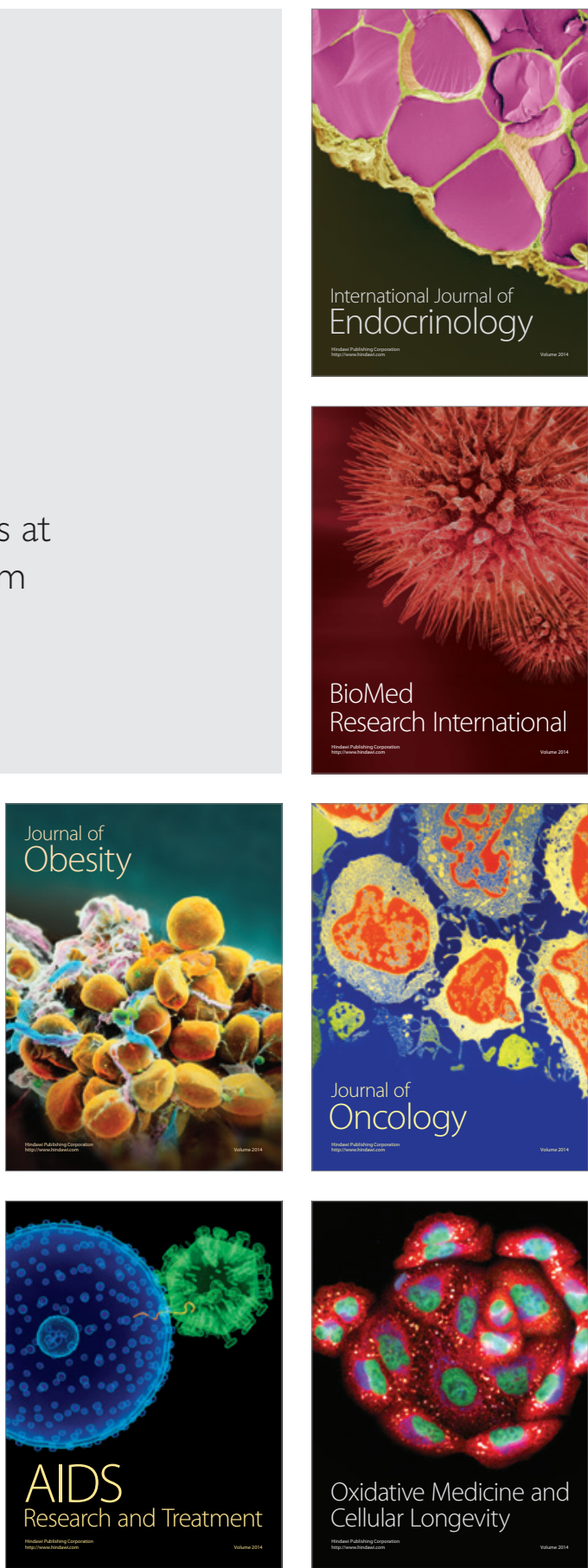